\title{
Kiyoo Wadati and the path to the discovery of the intermediate-deep earthquake zone
}

\section{Introduction}

The intermediate-deep earthquake zone is one of the most important geotectonic regions and provides much information about the internal processes of the Earth. It was discovered by Kiyoo Wadati in 1935, taking advantage of the dense and modern seismic observation network of the Central Meteorological Observatory of Japan. On his way to the discovery, Wadati wrote successive papers on the intermediate and deep earthquakes from 1928 to 1934, describing their frequency and spatial distributions. In the first paper (1928), he showed convincing evidence of deep earthquakes-deeper than $300 \mathrm{~km}$ - in central Honshu. He thus distinguished the deep earthquake zone traversing central Honshu, and compared it with the destructive earthquake zones. Then in the second paper (1929), he demonstrated the occurrence of deep earthquakes in the northern part of the Sea of Japan, and intermediate ones in the Japanese islands at depths between 100 and $200 \mathrm{~km}$. In his third paper (1931), he showed the occurrence of deep earthquakes in Kyushu.

In his fourth paper (1935), Wadati summarized these results and drew lines representing equal focal depths of the intermediate and deep earthquakes, which would later be called the Wadati-Benioff zone. The zone was an inclined surface from the trench toward the Asian continent and the Philippine Sea basin, so it was different from the deep earthquake zones described in the earlier papers.

In addition to those accounts, Wadati calculated the velocities of $\mathrm{P}$ and $\mathrm{S}$ waves to a depth of $500 \mathrm{~km}$, making use of the deep earthquakes; and he compared them with those produced by the distant earthquakes analysed in the first and second papers. In his third paper, he discussed the relations between the maximum amplitude and epicentral distance of the shallow, intermediate, and deep earthquakes.

Following Wadati's study, his colleague Hirokichi Honda also became interested in deep earthquakes, and especially in their mechanism. He showed that the horizontal components of maximum compression axes of intermediate and deep earthquakes were arranged perpendicularly to the lines of equal focal depth drawn by Wadati.

Prior to these publications, Toshi Shida gave a lecture on deep earthquakes in 1926, and left the lecture summary for the attendants. It was reprinted in 1937.

I shall show the process of the discovery of intermediate-deep earthquake zone, following the aforementioned Wadati's and Honda's papers. Then I shall introduce Shida's story concerning the recognition of deep earthquakes.

In what follows, I employ the symbols $\mathrm{P}$ and $\mathrm{S}$ for the longitudinal and transverse wave arrivals identified on seismograms, and also for the times at which those pulses arrive at an observatory.

\section{Wadati's first paper (1928)}

In this paper, Wadati (1928a) presented conclusive data for earthquakes occurring deeper than $300 \mathrm{~km}$, and for the existence of a deep earthquake zone crossing central Honshu. This paper was an English version of a paper written in Japanese in 1927.

\section{A. The North-Tazima Earthqualee.}

(i) Iso-(P-S)-Lines

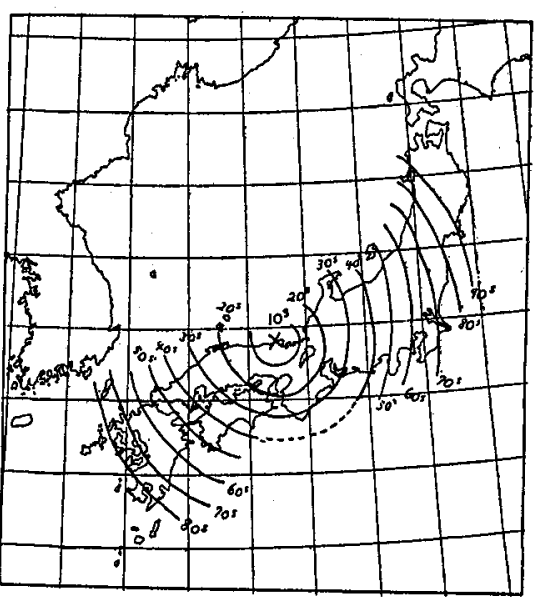

(ii) Iso-P-lines

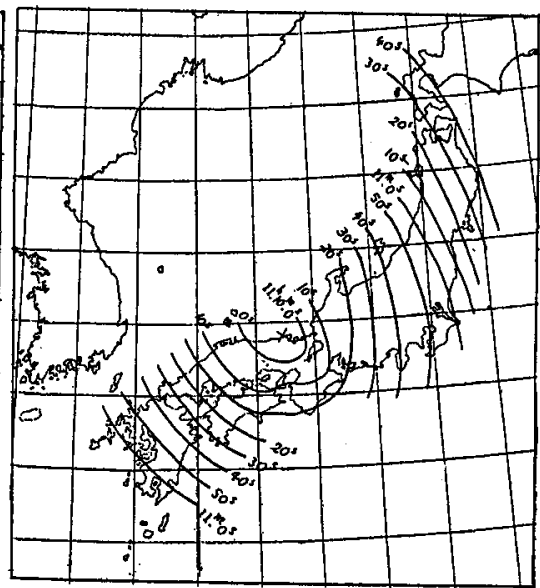

B. The Deep Earthquakes, Jan. 15th, 1927.

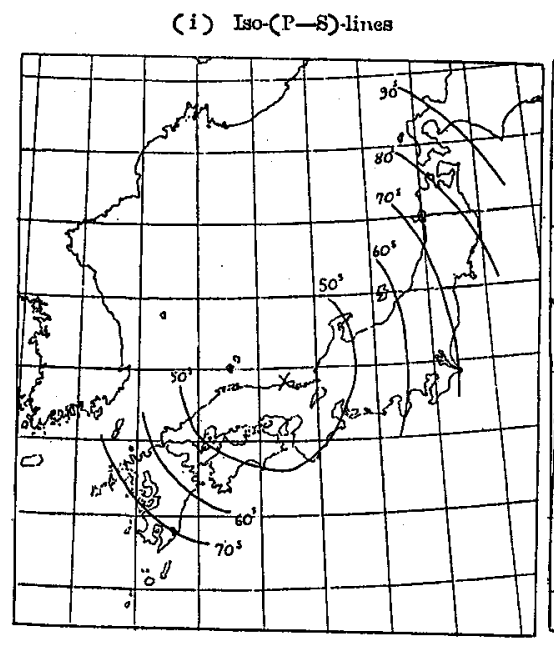

(ii) Iso-P-lines

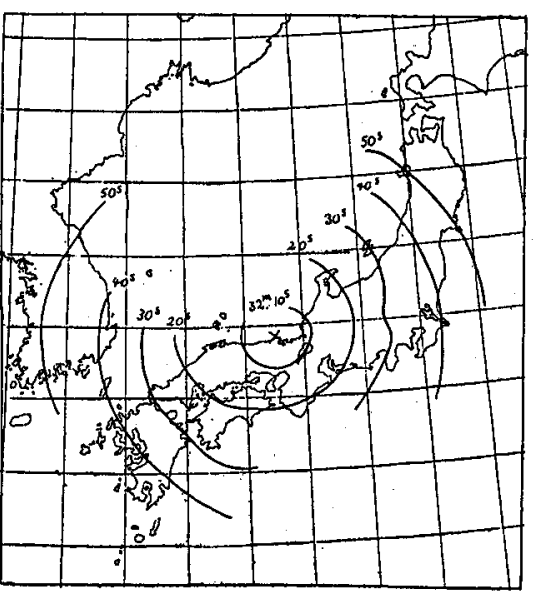

Figure 1 Curves of equal 'P-S' and of equal times of arrival of $P$ (Wadati, 1928a). A. The shallow North-Tazima Earthquake of 23 May, 1925. B. The deep earthquake of 15 January, 1927. 


\section{The occurrence of deep earthquakes}

Wadati showed curves of equal 'S minus P', and equal arrival-times of P-waves, for the North Tazima earthquake, which occurred on 23 May, 1925 and for the earthquake of 15 January, 1927; and he compared them with one another. The centres of the curves for the two earthquakes were close to one another, so their epicentres must also have been close. However, for the former earthquake the distances to the consecutive curves were less than they were for the latter earthquake, while 'S minus $\mathrm{P}^{\prime}$ at the epicentre was about 10 seconds for the former and 50 seconds for the latter (Figure 1).

Based on the travel-time curves of a hypothetical (P-S) wave, he showed that the former earthquake took place at a depth of $30 \mathrm{~km}$ and the latter was at a depth greater than $300 \mathrm{~km}$. The (P-S) wave was used for the detection of the hypocentre, as the arrival times of $\mathrm{P}$ and $\mathrm{S}$ waves were not accurately recorded at that time. The accuracy of the (P-S) wave was expected to be least of the order of 0.1 second, even though the absolute times were not so accurate. If Poisson's ratio is constant in the interior of the Earth, the hypothetical (P$\mathrm{S}$ ) wave followed Fermat's principle in a manner similar to that of the $\mathrm{P}$ and $\mathrm{S}$ waves, and travelled at the velocity

$$
\mathrm{v}=\mathrm{v}_{1} /\left(\mathrm{v}_{1} / \mathrm{v}_{2}-1\right)
$$

where $v$ is the velocity of (P-S) waves, $v_{1}$ is the velocity of longitudinal waves, and $\mathrm{v}_{2}$ is that of the transverse waves respectively.

The distribution of seismic intensity was different for the 1925 and 1927 earthquakes. For the former it was greatest near the epicentre and decreased gradually outward. For the latter, intensity II (3 or 4 in MSK scale) was observed not only near the epicentre but also in the Kanto district and on part of Kyushu, while intensity I (MSK 2) was noted in several places (Figure 2). The pattern of intensity for the 1927 shock was called an 'abnormal intensity distribution', which was thought to be characteristic of deep earthquakes.

The earthquake that occurred on 27 July, 1926 was another deep earthquake also thought to be worth detailed study. The curves for equal 'S minus $\mathrm{P}$ ' showed that the epicentre was located near Hikone to the east of Lake Biwa, central Honshu, and the hypocentre was calculated to be located at a depth of $339 \mathrm{~km}$, based on the travel-time curve of the (P-S) wave. The earthquake was accompanied by the abnormal intensity distribution.

Seismograms of the deeper earthquakes contained distinct $P$ and $S$ waves arrivals, and showed very short durations of pulsation, compared with those for shallow earthquakes. The period of the seismic waves was comparatively short, showing very rapid oscillations even when the distance from the epicentre was great. The usual dominant coda following the $\mathrm{P}$ and $\mathrm{S}$ arrivals was not observed, so $\mathrm{P}$ and $S$ waves were emanated, but not surface waves of any significance. Thus the seismograms of deep earthquakes were easily distinguished from those of shallow ones.

\section{The transverse deep-focus earthquake zone in relation to destructive earthquakes}

Wadati determined the hypocentres of 12 deep earthquakes between 1924 and 1927, and showed that they occurred in a deep earthquake zone traversing central Honshu, where several destructive earthquakes such as the Mino-Owari Earthquake of 28 October, 1891, the Anegawa Earthquake of 14 August, 1909, the Kanto Earthquake of 1 September, 1923, the Kita-Tazima Earthquake of 23 May, 1925, and the Kita-Tango Earthquake of 7 March, 1927 had occurred in recent times. A deep earthquake occurred fifty days before the Kita-Tango Earthquake, and another deep one took place four days after the Kita-Tazima Earthquake.

Based on those facts, Wadati supposed the occurrence of vertical stress propagation between shallow and deep earthquake zones.

\section{Wadati's second paper}

Wadati showed the occurrence of intermediate earthquakes at depths between 100 and $200 \mathrm{~km}$ in his second paper, published in 1929 . He added the information that deep earthquakes occurred in the Soya (La Perouse) Strait between Hokkaido and Sakhalin, and in the northern part of the Sea of Japan.

He calculated the velocity of seismic waves to a depth of 500 $\mathrm{km}$. The paper was an English version of two papers written in Japanese in 1928.

\section{The occurrence of intermediate and deep earthquakes}

Wadati determined the hypocentres of fourteen deep earthquakes from January 1927 to April 1928, and examined their frequency-distribution in relation to depth. He divided the earthquakes into three groups, namely shallow earthquakes shallower than $60 \mathrm{~km}$, intermediate ones from 60 to $300 \mathrm{~km}$, and deep ones deeper than $300 \mathrm{~km}$. He showed that more than $90 \%$ of earthquakes were shallow; intermediate ones were rather rare; and deep ones were quite frequent. This division was followed by Gutenberg and Richter (Richter, 1958).

A

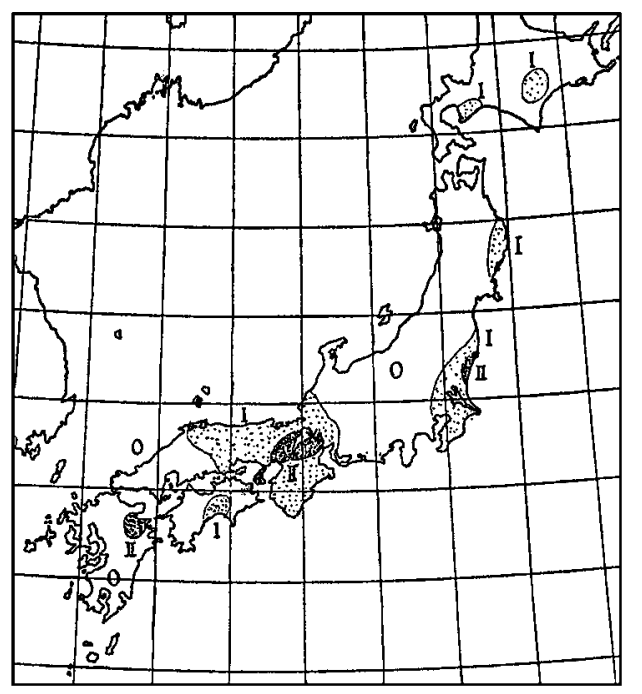

B

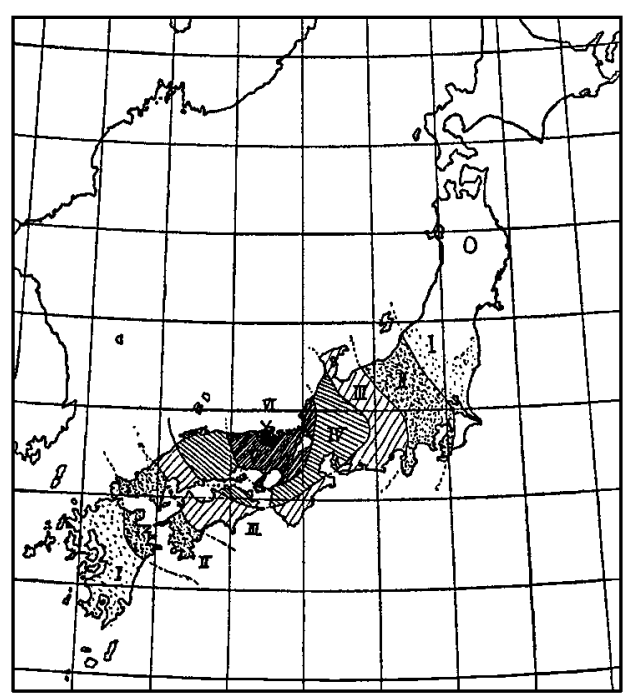

Figure 2 Distributions of seismic intensity (Wadati, 1928a). A. The deep earthquake of 27 July, 1926. B. The North-Tazima Earthquake of 23 May, 1925. 
Table 1 Three kinds of earthquakes and their characteristics (Wadati, 1928b).

\begin{tabular}{|c|c|c|c|c|}
\hline & & Land Earthquake & Deep Sea Earthquake & Deep-focus Earthquake \\
\hline \multirow[b]{2}{*}{ hypocenter } & location & $\begin{array}{l}\text { land and shallow sea } \\
\text { area }\end{array}$ & $\begin{array}{l}\text { deep sea area ( deeper } \\
\text { than } 5000 \mathrm{~m} \text { ) }\end{array}$ & $\begin{array}{l}\text { deeper part in the earth's } \\
\text { crust }\end{array}$ \\
\hline & depth & $\begin{array}{l}\text { very s h a } 110 \mathrm{w}, \\
\text { generally at depths } \\
20 \text { to } 40 \mathrm{~km}\end{array}$ & $\begin{array}{l}\text { probably very shallow, } \\
\text { shallower than } 20 \mathrm{~km}\end{array}$ & $\begin{array}{l}\text { deeper than } 300 \mathrm{~km} \text {, or } \\
\text { a little shallower }\end{array}$ \\
\hline \multirow{6}{*}{ seișmogram } & $P$ waves & $\begin{array}{l}\text { distinct or sometimes } \\
\text { indistinct initial } \\
\text { motion }\end{array}$ & indistinct initial motion & $\begin{array}{l}\text { very distinct initial motion } \\
\text { large and small amplitude } \\
\text { types }\end{array}$ \\
\hline & $S$ waves & generally distinct & $\begin{array}{l}\text { generally indistinct, } \\
\text { probably appear more } \\
\text { than } 2000 \mathrm{~km} \text { in epicentral } \\
\text { distance }\end{array}$ & $\begin{array}{l}\text { very distinct and large } \\
\text { amplitude }\end{array}$ \\
\hline & $\begin{array}{l}\text { surface } \\
\text { waves }\end{array}$ & common & predominant & do not appear \\
\hline & frequency & average & low & high \\
\hline & duration & average & long & short \\
\hline & P-S time & $\begin{array}{l}\text { generally determinate, } \\
\text { Coefficient } 7.42 \text { for } \\
\text { the epicentral distance } \\
\text { in Omori's formula is } \\
\text { applicable. }\end{array}$ & not easy to determine & $\begin{array}{l}\text { very easy to determine, } \\
\text { The time is generally longer } \\
\text { than } 25 \text { seconds. Coefficient } \\
\text { for the epicentral distance in } \\
\text { Omori's formula is about } \\
10 \text {. }\end{array}$ \\
\hline \multicolumn{2}{|c|}{ tremor } & $\begin{array}{l}\text { abrupt and disastrous } \\
\text { near the epicenter in } \\
\text { big earthquake }\end{array}$ & weak and slow tremor & $\begin{array}{l}\text { generally weak but sudden } \\
\text { tremor }\end{array}$ \\
\hline \multicolumn{2}{|c|}{ occurrence } & $\begin{array}{l}\text { areas along coasts, } \\
\text { rivers and straits }\end{array}$ & deep sea tmches & $\begin{array}{l}\text { deep earthquake zones (?) } \\
\text { north part of the Japan Sea }\end{array}$ \\
\hline \multicolumn{2}{|c|}{ process } & $\begin{array}{l}\text { many after-shocks } \\
\text { following big } \\
\text { earthquake }\end{array}$ & $\begin{array}{l}\text { multiple shocks in nearly } \\
\text { equal scale }\end{array}$ & single occurrence \\
\hline \multicolumn{2}{|c|}{ casualty } & $\begin{array}{l}\text { heavy casualties in } \\
\text { big earthquake and } \\
\text { occasionally tsunami }\end{array}$ & occasionally tsunami & no casualty \\
\hline
\end{tabular}

Wadati pointed out again in the second paper that the shallow earthquakes were accompanied by dominant surface waves, and that the deep ones showed distinct $\mathrm{P}$ and $\mathrm{S}$ waves. Deep and most intermediate earthquakes produced an abnormal intensity distribution, although some intermediate ones did not cause such distribution. The characters of shallow and deep earthquakes are summarised in Table 1, which was presented by Wadati (1928b) in Japanese.

To the deep earthquakes in the zone crossing central Honshu, Wadati added the deep earthquakes in the Soya Strait and northern part of the Sea of Japan. He showed that the intermediate earthquakes occurred in north Nagano, Niigata, and Kanto areas, central Honshu, and Hachijo-jima in the Izu Islands.

\section{Velocity distribution of seismic waves}

Zöppritz and Geiger, and Mohorovičić had previously determined the velocity-distribution of seismic waves in relation to depth, based on the travel-time curves for distant earthquakes. Wadati calculated the velocity-distribution of seismic waves to a depth of $500 \mathrm{~km}$, based on the travel-time curves of the deep earthquakes, and compared it with those obtained by Zöppritz and Geiger, and Mohorovičić. They were nearly coincident, though some small differences were found.

\section{Wadati's third paper}

Wadati (1931) discussed the spatial distribution of the shallow, intermediate, and deep earthquakes that occurred in Japan between 1927 and 1931, and indicated the occurrence of deep earthquakes in Kyushu. He discussed the causes of abnormal distribution of intensity accompanying intermediate and deep earthquakes. He showed amplitude-distance curves for shallow, intermediate, and deep earthquakes.

\section{Shallow, intermediate, and deep earthquakes}

Wadati indicated 136 hypocentres of the shallow, intermediate, and deep earthquakes from January 1928 to June 1931, and seven intermediate earthquakes from 1927 to July 1931. He again stated that the shallow earthquakes were dominant, but that the earthquakes deeper than $300 \mathrm{~km}$ were quite frequent.

Wadati also described the earthquakes' spatial distribution. The shallow ones occurred along the Pacific coast but were rare along the Sea of Japan and in the Japanese islands. The deep earthquakes occurred frequently in the north and central parts of the Sea of Japan, and in the northern Hokkaido. The deep earthquakes (deeper than $300 \mathrm{~km}$ ) occurred in north Kyushu. The intermediate earthquakes were recorded in the area of the Sea of Japan.

\section{Cause of abnormal intensity distribution}

Wadati gave attention to the dominance of high-frequency seismic waves in the area showing abnormally high intensity, and he pointed out that the area showing the abnormal intensity coincided with an area of high gravity. He attributed the high intensity to a hard layer in the Earth's crust, and low intensity to a soft one absorbing the high-frequency seismic waves in the crust. It should be remarked 
that the Earth's crust in Wadati's sense included the upper mantle in addition to the crust in the modern sense.

\section{Amplitude-distance curves}

Wadati showed the relation between maximum amplitude and epicentral distance for 31 shallow earthquakes. He plotted the maximum ground motion at each station as ordinate (using a logarithmic scale) with the corresponding epicentral distances as abscissa. He pointed out that all curves were concave upwards, and their curvatures were more acute according to the size of the earthquakes. Seismograms of the shallow earthquakes showed the predominance of surface waves and the maximum amplitudes were interpreted as being due to those waves, except at the areas near epicentres.

The relations were examined for five intermediate and five deep earthquakes. Wadati pointed out that the curves were convex upwards near the epicentres and decreased more gradually than those for the shallow earthquakes; and these characters were more conspicuous for the deeper ones. The large amplitudes for the intermediate and deep earthquakes were attributed to body waves.

Wadati sought to apply this diagram to the estimation of the scale of destructive earthquakes. This diagram could be compared with Richter's magnitude-scale, published in 1935.

\section{Wadati's fourth paper}

Wadati published his fourth paper in 1935, in which the frequency-distribution of earthquakes occurring between 1924 and 1934, and the contour lines of equal focal depths of intermediate and deepearthquakes, were plotted. They revealed inclined surfaces dipping away from the oceanic trenches - the planes that came in the West to be called the Benioff Zones following Benioff's publication in 1955. The name was subsequently changed to Wadati-Benioff Zones, thus acknowledging their discovery by Wadati two decades earlier.

\section{Lines of equal focal depth}

Hypocentres of 42 deep earthquakes between 1905 and 1923, and 62 deep and 28 intermediate earthquakes between 1924 and April 1934 were plotted, showing the frequency distribution of their focal depths and their geographical distributions. The data before and after 1924 were shown separately, as the seismological observatories were better equipped with Wiechert seismographs and offered more reliable data after 1924.

The data indicated the most frequent occurrences were at depths of 300 to $400 \mathrm{~km}$ and the least were at about $200 \mathrm{~km}$. Eight earthquakes were deeper than $500 \mathrm{~km}$, and the deepest was at $660 \mathrm{~km}$. Most of the deep earthquakes occurred along the Transverse and Soya deep-focus earthquake zones. The former zone extended over $2000 \mathrm{~km}$ from Vladivostok to the Bonin Islands, traversing central Honshu. The latter one ran northeast along the Chishima Islands, extending from the northern part of the Sea of Japan through the Strait of Soya (La Pèrouse). In addition to those zones, the Kyushu deep earthquake zone was revealed near the Ryukyu Islands, extending to northern Kyushu. Based on the depth of the hypocentres of these earthquakes, the lines of equal focal depth were shown, at which intermediate and deep earthquakes occurred frequently ( Figure 3). The lines ran along the Chishima (Kurile) Islands, Hokkaido, northeast Honshu, and the IzuBonin Islands, and dipped away from the Chishima, Japan and Izu-Ogasawara trenches towards the north, west, and southwest. Other lines ran along the Ryukyu Islands and got deeper from the Ryukyu trench toward WNW.
The volcanic zones running along the Japanese Islands were found to coincide with the intermediate earthquakes' lines of equal focal depth.

\section{Formation of the intermediate-deep earthquake zones}

Wadati thought that the inclined intermediate-deep earthquake zones were regions of weakness which suggested the possibility of traces of drift of the Japanese islands.

Further, Wadati suggested some common force giving rise to the earthquakes and the volcanism, judging from the close relationship between intermediate earthquakes and volcanic zones.

\section{Honda's study of earthquake mechanisms}

Honda tried to analyse the $\mathrm{P}$-wave radiation pattern of the intermediate and deep earthquakes, and published a paper on the mechanism of deep earthquakes in 1934, in which he discussed the spatial distribution of forty-five deep earthquakes deeper than $100 \mathrm{~km}$ that occurred between 1927 and 1933. He pointed out that they took place along the Principal (Wadati's Transverse) deep earthquake zone, crossing central Honshu NNW-SSE, and the Soya deep earth-

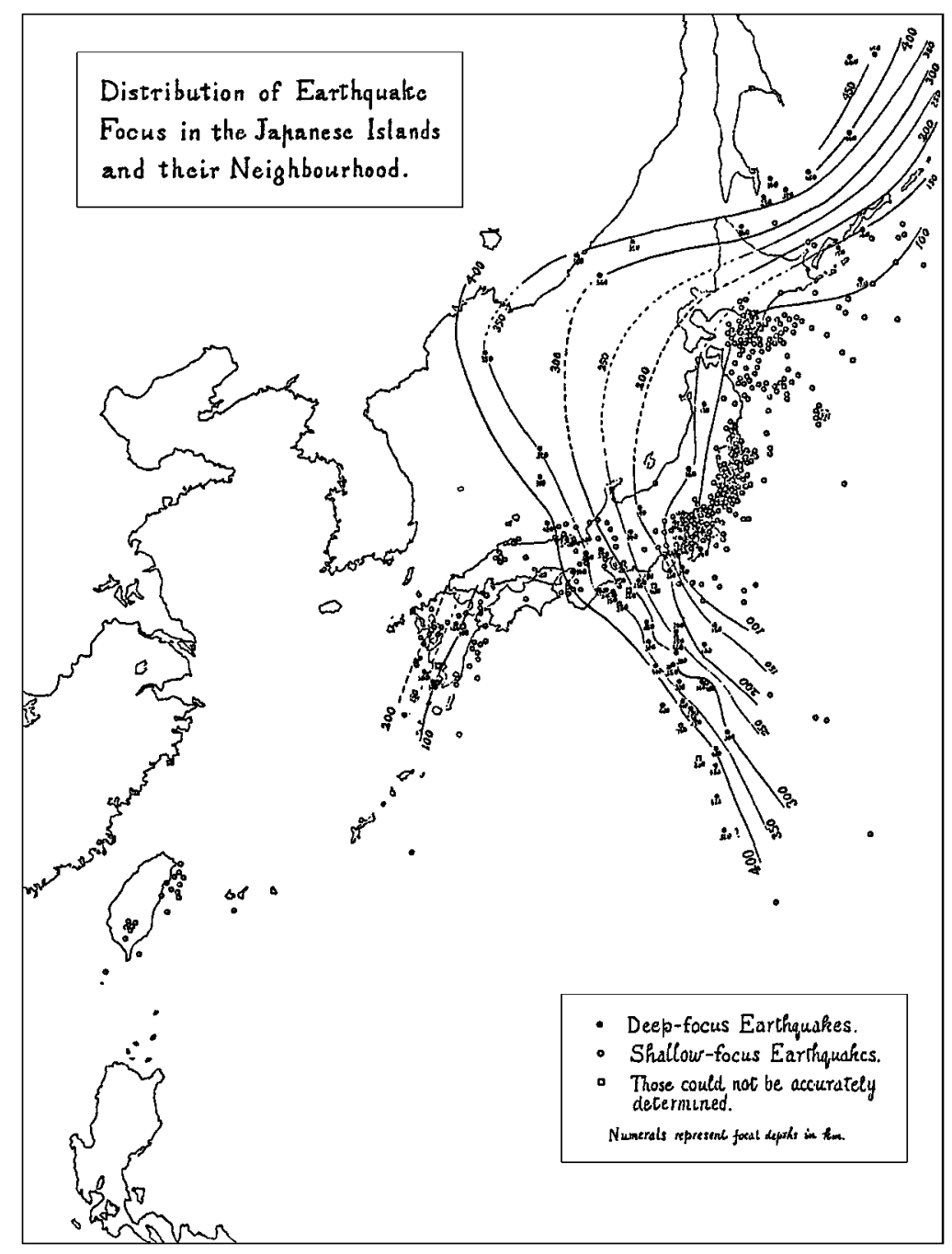

Figure 3 Distribution of earthquakes and lines of equal focal depth for intermediate and deep earthquakes (Wadati, 1935). 
quake zone, crossing north Hokkaido ENE-WSW. These zones were to be correlated with those in Wadati's fourth paper, published several months later in 1935. Several intermediate earthquakes to the east of those zones shown in the figure seem to suggest some possibility of the discovery of the dipping intermediate-deep earthquake zone by Honda.

Based on the distribution of initial motions of P-waves, Honda gave the directions of maximum pressure and nodal lines (separating the four fields of initial compressions or dilatations received at observatories) for ten earthquakes occurring at depths between 100 and $250 \mathrm{~km}$, and for 38 ones deeper than $250 \mathrm{~km}$. He showed that the horizontal components of maximum compression axes of intermediate and deep earthquakes were arranged perpendicularly to the lines of equal focal depth drawn by Wadati. Honda discussed the stress state in the southern half of the principal deep earthquake zone, where many earthquakes occurred, and supposed that there was some driving-force acting on a large scale in the deeper part of the Earth.

Honda also reported that the nodal planes ran mostly in a N-S or NNW-SSE direction and that the maximum pressures were directed 'westerly downward', while the maximum tension was 'easterly downward'. Such states of stress suggested a sheared state in the deeper part of the Earth, such that the eastern part was being pushed down and the western part upwards; or the shallower part moved westwards and the deeper one moved eastwards under the Japanese islands and surrounding areas.

\section{Shida's study of deep earthquakes}

More than ten years before the presentation of the convincing evidence for deep earthquakes, Shida noticed them while working at the Imperial University of Kyoto. He paid attention to a strong earthquake that occurred on 21 January, 1906, which shook seismographs over the whole globe. Wiechert described it, revealing the clear evidence for reflection and refraction of seismic waves in the Earth's interior.

Shida came to the conclusion that the earthquake must have taken place deep in the Earth, as the time difference of arrival-times among the observatories in the Japanese islands was very small, and the arrival-time was ten seconds or more earlier, compared with those of ordinary earthquakes for the observatories in foreign countries, according to the data from the International Seismological Summary.

Shida traced the epicentre to central Honshu, considering chiefly the first motion of the seismic waves, but he hesitated to publish the result at that time since the isostatic theory held that the Earth must be statically stable below about $120 \mathrm{~km}$. Subsequently, he found many earthquakes of this kind for a period of over seventeen years, but he could not present convincing evidence to prove the occurrence of the deep earthquakes as their epicentres were traced to offshore areas.

A strong earthquake shook the Kansai area, central Honshu, on 27 July, 1926, but its epicentre was announced differently by the Central Meteorological Observatory and other institutes. Shida fixed the hypocentre near Lake Biwa, at a depth of $260 \mathrm{~km}$. The epicentre was determined, based on the initial motion of seismic waves for different observatories in the Japanese Islands. The study of the distribution of the first motion of earthquakes was Shida's favourite field, so he used to pay close attention to the matter. He read a paper on the discovery of deep earthquakes at the opening ceremony of the Beppu Geophysical Laboratory, the Imperial University of Kyoto on 28 October, 1926, and it was distributed to those present, and reprinted posthumously in 1937 in Geophysics, the Japanese-language journal of geophysics of the Imperial University of Kyoto. Shida showed the deep earthquake zone traversing central Honshu, where recent destructive earthquakes such as the Mino-Owari and the Kanto earthquakes had occurred. He insisted that the earthquakes and vol- canoes must be caused by some common driving force, acting at the approximate depth of the intermediate-depth earthquakes.

Wadati referred to Shida's study and showed the directions of initial motion of seismic waves in the table in his first paper.

\section{Seismology in the Central Meteorological Observatory in the 1920s and 1930s}

The Kanto earthquake occurred on 1 September, 1923, and caused great suffering in South Kanto including Tokyo, Yokohama, and their environs. The director of the Central Meteorological Observatory, Takematsu Okada, pushed forward the work of modernisation of the seismological network with enthusiasm, and encouraged the work of the young scientists in the observatory (Suda, 1968). Thus a dense and modern seismic observation network was available to the seismologists in the observatory, which was equipped with Wiechert, Galitzin, and Mainka seismographs.

Under such circumstances, many pioneering studies were published by seismologists and geophysicists in the observatory. Wadati's study was one of the most fruitful outcomes of the work of the Central Meteorological Observatory in the 1920s and 1930s. In addition to his investigations of deep earthquakes, Wadati made several other important contributions to seismology. He found the Mohorovičić discontinuity in the Japanese islands (Wadati, 1927b) and calculated the travel-time curves in the Earth's interior (Wadati et al., 1933; Wadati, 1933a, 1933b; Wadati and Oki, 1933; Wadati and Masuda, 1933, 1934), analogous to those of Gutenberg and Jeffreys.

Honda studied earthquake mechanisms at the Central Meteorological Observatory as his life's work. He showed more clearly the arrangement of the horizontal components of maximum compression axes of intermediate and deep earthquakes in relation to the intermediate-deep earthquake zones in later years (Honda and Masatsuka, 1940).

Most of those works were published in the Geophysical Magazine, the foreign-language journal published by the Central Meteorological Observatory from 1926 onwards.

In this way, the work of Wadati and Honda paved the way in the 1930s to the new concepts of global tectonics that were developed after the War.

\section{Biographical notes}

\section{Toshi Shida (1876-1936)}

Shida was born in Sakura, Chiba Prefecture, in 1876, and graduated from the Institute of Physics of the Imperial University of Tokyo in 1901. He was a professor of geophysics at the Imperial University of Kyoto. He subsequently succeeded to the Shimogamo Geophysical Observatory from the Imperial Seismological Investigation Committee, and founded the Beppu Geophysical Observatory in 1924, the Aso Volcanological Observatory in 1928, and the Abuyama Seismological Observatory in 1931.

\section{Kiyoo Wadati (1902-1995)}

Wadati was born in Nagoya City in 1902, and graduated from the Institute of Physics of the Imperial University of Tokyo in 1925. After graduation, he was engaged in the observation of earthquakes at the Central Meteorological Observatory. He was a director of the Central Meteorological Observatory, a director-general of the Japan Meteorological Agency, and President of Saitama University. 


\section{Hirokichi Honda (1906-1982)}

Honda was born in Tottori Prefecture in 1906, and graduated from the Institute of Physics of the Imperial University of Tokyo in 1929. He was engaged in the observation of earthquakes in the Central Meteorological Observatory from 1929. From 1951, he was a professor of geophysics at Tohoku and Tokyo Universities.

\section{Acknowledgments}

The author would like to express his cordial thanks to Professor David Oldroyd for the recommendation of writing the paper. He is indebted to Drs. M. Omori, T. Kutsukake, M. Yajima, and A. A. Day who have critically reviewed the manuscript. He thanks Ms. Tomomi Isono of the Japan Meteorological Agency for her kind preparation of bibliographical information.

\section{References}

Benioff, H., 1955, Seismic evidence for crustal structure and tectonic activity: Geological Society of America, Special Papers 62, pp. 61-74.

Honda, H., 1934, On the mechanism of deep earthquakes and the stress in the deep layer of the Earth's crust: Geophysical Magazine, v. 8, pp. 179-185.

Honda, H., and A. Masatsuka, 1940, On the earthquake generating stress in the Earth's crust of the Japanese islands and environs: Quarterly Journal of Seismology, v. 11, pp. 183-216 and 546-548 (in Japanese).

Richter, C., 1958, Elementary Seismology: San Francisco, Freeman and Co.

Shida, T., 1929, Review of the study of rigidity of the Earth and the initial motion of seismic waves: Toyo Gakugei Zasshi (East Asian Journal of Art and Science), v. 45, pp. 275-289 (in Japanese).

Shida, T., 1937, An address at the opening ceremony of the Beppu Geophysical Institute, Kyoto University (a proposal of deep earthquake): Geophysics, v. 1, pp. 1-5 (in Japanese).

Suda, T., 1968, A Biography of Takematsu Okada: Tokyo, Iwanami Publishing Company (in Japanese).

Wadati, K., 1927a, The occurrence of deep earthquakes, and study on them: Journal of the Meteorological Society of Japan, v. 5, pp. 119-146 (in Japanese)
Wadati, K., 1927b, On the Mohorovičić wave observed in Japan: Geophysical Magazine, v. 1, pp. 87-96.

Wadati, K., 1928a, Shallow and deep earthquakes: Geophysical Magazine, v. 1 , pp. 162-202.

Wadati, K., 1928b, On the peculiarity of deep-sea earthquakes and three kinds of earthquakes: Journal of the Meteorological Society of Japan, v. 6, pp. 1-43 (in Japanese).

Wadati, K., 1928c, Study of deep earthquakes (2nd paper): Journal of the Meteorological Society of Japan, v. 6, pp. 192-216 (in Japanese).

Wadati, K., 1928d, Study of deep earthquakes (3rd paper): Journal of the Meteorological Society of Japan, v. 6, pp. 226-248 (in Japanese).

Wadati, K., 1929, Shallow and deep earthquakes (2nd paper): Geophysical Magazine, v. 2, 1-36.

Wadati, K., 1931, Shallow and deep earthquakes (3rd paper): Geophysical Magazine, v. 4, pp. 231-283.

Wadati, K., 1933a, On the travel -time of earthquake waves (part I): Geophysical Magazine, v. 7, pp. 101-111.

Wadati, K., 1933b, On the travel-time of earthquake waves (part II ): Geophysical Magazine, v. 7, pp. 113-137.

Wadati, K., 1935, On the activity of deep-focus earthquakes in the Japan islands and neighbourhoods: Geophysical Magazine, v. 8, pp. 305-325.

Wadati, K. and K. Masuda, 1933, On the travel time of earthquake waves (part V): Geophysical Magazine, v. 7, pp. 269-290.

Wadati, K., and K. Masuda, 1934, On the travel time of earthquake waves (part VI): Geophysical Magazine, v. 8, pp. 187-194.

Wadati, K., and S. Oki, 1933, On the travel time of earthquake waves (part IV): Geophysical Magazine, v. 7, pp. 139-153.

Wadati, K., Sagisaka, K., and Masuda, K., 1933, On the travel time of earthquake waves (part II): Geophysical Magazine, v. 7, pp. 87-99.

\section{Yasumoto Suzuki}

Secretary-General of the Japanese Association for the History of Geological Sciences

Geothermal Energy Research and Development Company

Kyodo Building, 11-7

Kabuto-cho, Nihonbashi, Chuo-ku

Tokyo 103-0026

JAPAN

\title{
CALL FOR PAPERS
}

Episodes is the quarterly science and news journal of the International Union of Geological Sciences (IUGS). It focuses on the publication of results of scientific research and other information addressing issues of interest to the global earth-science community. Special emphasis is given to topics involving geological aspects of population growth and economic development and their resulting impacts on or implications for society. As the principal publication of the IUGS, Episodes also carries information about IUGS scientific programs and activities to the extent necessary to communicate effectively with the worldwide IUGS constituency.

Contributions of the following types of manuscripts are here solicited:

- Review papers

- scientific articles

- conference reports

- news and views

- letters to editor

- book reviews

- noteworthy new publications, including national or regional geologic maps

Episodes also invites photos or other images for the front cover. Photos must be of high technical quality and tell an interesting geological story. A color transparency and one color print (at least $9 \mathrm{~cm} \times 12.6 \mathrm{~cm}$ ) are required for submission, which should be supplemented with a short explanatory paragraph (no more than 100 words).

Please address all contributions to:

\author{
The Editor \\ Episodes \\ P. O. Box 823, 26 Baiwanzhuang Road \\ 100037 Beijing, CHINA \\ Tel: +86-10-68320827; 86-10-68329084 \\ Fax: +86-10-68328928; \\ E-mail: episodes@public2.bta.net.cn
}

